\title{
Analysis and location of Turn-To-Turn short circuit of rotor windings in generator
}

\author{
Yucheng Zhang ${ }^{1, *}$, Zenghuan Sun ${ }^{2}$ \\ ${ }^{1}$ HuaDian electric power research institute, Hangzhou China \\ ${ }^{2}$ Lianhe Taize Environmental Science and Technology Development Co Ltd,Jinan China
}

\begin{abstract}
With the increase of generator running time, the probability of generator rotor problems increases constantly. In this paper, a generator is taken as an example. During maintenance, the generator is found to have the evidence of turn-to-turn short circuit of rotor windings by the repetitive surge oscilloscope method, which is verified by the AC impedance power loss test of the rotor winding. The position of turnto-turn short circuit is determined by the inter-pole voltage method and the coil voltage method. The accuracy of the test method is further verified by the generator rotor's return repair.
\end{abstract}

\section{Introduction}

In the background of electricity market developing slowly and frequent participation of thermal power generating units in peak-adjusting depth, the annual start and stop times of generating units are increasing year by year, and the failure rate of generator rotor is on the rise, among which turn-to-turn short circuit accounts for the largest proportion. The turn-to-turn short circuit fault of the rotor winding that causes the generator to turn slightly has little influence on the normal operation of the generator set and the fault features are not obvious, so it is often ignored in operation. However, if the generator runs for a long time in the state of turn-to-turn short circuit fault, the excitation current of the rotor will significantly increase. The reactive power will decrease, and the bearing unbalanced vibration caused by the uneven distribution of internal thermal stress will significantly increase. Once the severity of the turn-toturn short circuit fault of the rotor windings increases, it will also lead to one or even two points grounding fault of the rotor, leading to the magnetization of the rotor shaft, and in serious cases, it will also burn the shaft neck and bearing bush, posing a great threat to the safe and stable operation of the unit itself。

There are some main reasons for rotor turn short circuit fault: (1)The number of thermal expansion of the windings increases, and the displacement between turns increases; (2) The rotor end windings are almost exposed, oil and foreign matter are easy to invade, uneven cooling resulting in deformation of the windingss; (3) Fixed end loose, the process of starting and stopping by centrifugal force, thermal stress caused by the action of insulation damage.

This paper finds out that there is a sign of turn-toturn short circuit in the rotor windings by using repeat pulse method. Combined with the ac impedance power loss test of the rotor windings, the position of turn-toturn short circuit is determined by the inter-pole voltage method and the coil voltage method. In the later period, the shutdown treatment period is short and the effect is pretty good.

\section{Test principle}

For the diagnosis of turn-to-turn short circuit fault, the methods recommended in DL/T 1512-2016 Guidelines for Judging Turn-to-turn Short Circuit Fault of Hidden Pole Synchronous Generators rotors, mainly include alternating impedance and power loss method, inter-pole voltage method, coil voltage method, detection coil waveform method, repeat pulse method, etc.

\subsection{The repetitive surge oscilloscope generation}

The basic principle of repetitive surge oscilloscope generation (RSO test) is to inject human pulse signal at both ends of the rotor windings, namely the low voltage pulse with steep leading edge, and judge whether there is turn-to-turn short circuit fault of the rotor windings by analyzing the superposition waveform of human point pulse signal and reflected wave. In this kind of pulse signal, the rotor windings can be regarded as a section of transmission line, and its impedance distribution is determined by the shape of the rotor windings. Due to the symmetry of the rotor windings structure, the waveforms of the two injection points are highly consistent under normal conditions. The characteristic waveform, that is, the subtractive wave of the two injector point waveforms, appears as a straight line. When there is a turn-to-turn short circuit or a shortcircuit to the ground, the changes in the distribution of the windings impedance will generate reflected waves. As long as the short circuit point does not occur at the

\footnotetext{
* Corresponding author: yucheng-zhang@chder.com
} 
middle point of the two ends of the windings, and the reflected wave arrives at the two ends of the rotor with different propagation time, the two ends will present different composite waves, which are represented as spikes in the characteristic waveform. The amplitude and position of characteristic waveform peak are related to the number of turns and position of short circuit. The greater the number of turns, the greater the amplitude, and the position of the peak reflects the relative position of the short circuit point on the windings.

\subsection{Inter-pole voltage method and coil voltage method}

The principle of inter-pole voltage method and coil voltage method is to apply $100-400 \mathrm{~V}$ power frequency voltage at the poles of generator windingss and measure inter-pole voltage drop and corresponding coil voltage drop, and use their symmetry to determine whether there is an interturn short circuit. This method can only be performed when the rotor is outside the bore of the generator. A voltage regulator is applied to the rotor windingss by means of a slip ring and a conductive screw. The inter-pole voltage is measured with a probe under the rotor guard ring. When the voltage difference between electrodes exceeds $3 \%$ of the maximum voltage, it is judged to have a turn-to-turn short circuit

\section{Case analysis}

The no. 2 generator of the power plant owned by a power generation group is a three-phase, two-pole and hidden pole rotor synchronous generator of Type QFSN-1050-227 produced by Dongfang Electric Plant and was released in 2012. The ac impedance and power loss test of the rotor was carried out during the overhaul in October 2019. Compared with the historical data, the AC impedance was reduced by more than $8 \%$, while the loss was increased by more than $8 \%$ compared with the historical data. The AC impedance and power loss test were unqualified. The phenomenon of turn-to-turn short circuit in generator rotor was further judged by repetitive surge oscilloscope test, and the position of turn-to-turn short circuit was determined by inter-pole voltage method and coil voltage method. The following is the detailed introduction of the test.

\subsection{AC impedance and power loss test}

According to Guidelines for 《The Diagnosis of Turnto-turn Short Circuit Fault of Hidden Pole Synchronous Generator rotors》(DL/T 1525-2016), "When one of the following situations occurs, it shall be judged as a fault: 1) The AC impedance value shall be reduced by more than $10 \%$ compared with the factory data or historical data; 2) Loss increases by more than $10 \%$ compared with ex-factory data or historical data; 3) When the AC impedance is reduced by more than $8 \%$ compared with the factory data or historical data, and the loss is increased by more than $8 \%$ compared with the factory data or historical data;" . The ac impedance and power loss test of the rotor are shown in Table 1. Compared with the test data of AC impedance and power loss in September 2014 overhaul and October 2019 overhaul, the ac impedance and historical data are reduced by more than $8 \%$, while the loss and historical data are increased by more than $8 \%$. The AC impedance and power loss test are unqualified.

Table 1 AC Impedance And Power Loss Test Data

\begin{tabular}{|c|c|c|c|c|c|c|c|c|}
\hline \multirow{2}{*}{$\begin{array}{l}\text { Voltage } \\
(10 \mathrm{~V})\end{array}$} & \multicolumn{2}{|c|}{ Current (A) } & \multicolumn{3}{|c|}{$\begin{array}{l}\text { AC impedance } \\
(\Omega)\end{array}$} & \multicolumn{3}{|l|}{$\begin{array}{l}\text { Power } \\
\text { (W) }\end{array}$} \\
\hline & 2014.09 & 3-Oct-19 & $\begin{array}{l}\text { Septembe. } 20 \\
14 \text { overhaul }\end{array}$ & 3-Oct-19 & $\begin{array}{l}\text { Deviati } \\
\text { on } \\
\text { rate(\%) }\end{array}$ & $\begin{array}{l}\text { Septembe. } 20 \\
14 \text { overhaul }\end{array}$ & 3-Oct-19 & $\begin{array}{l}\text { Deviation } \\
\text { rate }\end{array}$ \\
\hline 2 & 313 & 3.52 & 6.38 & 5.68 & -10.97 & 38 & 44 & 15.79 \\
\hline 4 & 6.01 & 6.57 & 6.65 & 6.08 & $-8.57 \%$ & 147 & 160 & $8.84 \%$ \\
\hline 60 & 8.94 & 9.77 & 6.71 & 6.14 & $-8.49 \%$ & 332 & 364 & $9.64 \%$ \\
\hline 80 & 11.66 & 12.82 & 6.86 & 6.24 & $-9.04 \%$ & 569 & 640 & $12.48 \%$ \\
\hline 100 & 14.3 & 15.7 & 6.99 & 6.36 & $-9.01 \%$ & 880 & 982 & $11.59 \%$ \\
\hline 120 & 16.92 & 18.43 & 7.09 & 6.51 & $-8.18 \%$ & 1254 & 1382 & $10.21 \%$ \\
\hline 140 & 19.36 & 21.03 & 7.23 & 6.65 & $-8.02 \%$ & 1673 & 1856 & $10.94 \%$ \\
\hline
\end{tabular}




\subsection{RSO test}

RSO test results are shown in Figure.1. The waveform with large amplitude is the waveform returned by the inner rotor and outer slip ring, while the waveform with small amplitude is the waveform synthesized after the waveform returned by the inner rotor and outer slip ring is subtracted. According to Figure.1, it can be found that the two returned pulse waveforms cannot be well coincident, and the resultant waveform is $315.995 \mathrm{mV}$ spike pulse at the highest, which indicates that there is an turn-to-turn short circuit fault with gold property or nonmetal property in the rotor windings.

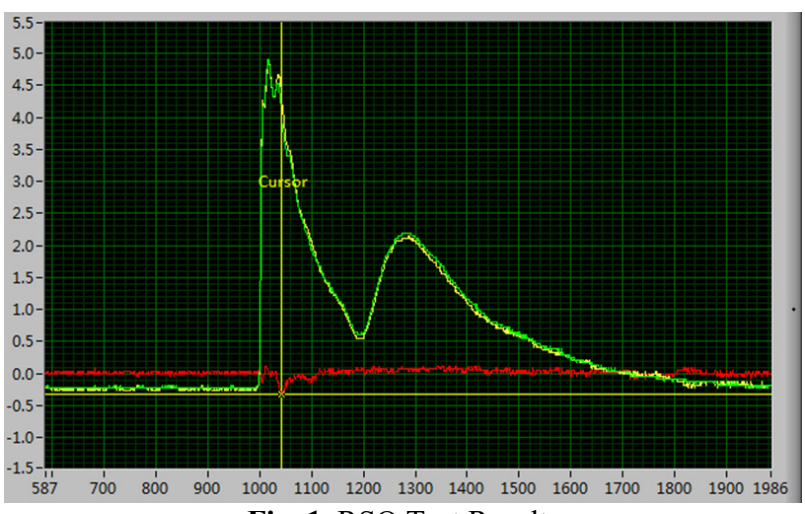

Fig. 1. RSO Test Results

\subsection{Inter-polar voltage method and coil voltage method}

The test results of inter-polar voltage method are shown in Table 2. When the inter-polar voltage difference exceeds $3 \%$ of the maximum voltage value, it is judged to have a turn-to-turn short circuit. In this test, there is a deviation of up to $13.6 \%$ in the inner and outer ring voltage drops, far exceeding the standard value. Combined with the test data of repetitive surge oscilloscope method, the evidence of turn-to-turn short circuit in generator rotor can be determined.

Table 2. Test results of inter-polar voltage method (external application voltage 200VAC)

\begin{tabular}{|c|c|c|c|c|}
\hline Measuring position 1 & Voltage(V) & Measuring position 2 & Voltage(V) & $\begin{array}{c}\text { Voltage } \\
\text { differential }\end{array}$ \\
\hline Positive pole-pole midpoint & 110 & Negative pole -pole midpoint & 95 & $13.6 \%$ \\
\hline
\end{tabular}

The test results of coil voltage method are shown in Table 3. Among them, the voltage drop deviation of No. 2, 4 and 6 coils exceeds the standard value, and the voltage drop deviation of No. 4 coil exceeds the standard value by 15.5 times. It can be concluded that there is a serious turn-to-turn short circuit in No. 4 coil.

Table 3. Coil voltage test data (external application voltage 100VAC)

\begin{tabular}{|c|c|c|c|c|c|}
\hline NO. & $\begin{array}{c}\text { Position1 } \\
(\text { Out })\end{array}$ & $\begin{array}{c}\text { Voltage } \\
(\mathrm{V})\end{array}$ & $\begin{array}{c}\text { Position2 } \\
(\text { In) }\end{array}$ & Voltage (V) & $\begin{array}{c}\text { Voltage } \\
\text { differential } \\
(\%)\end{array}$ \\
\hline 1 & Coil1-Coil2 & 5.35 & Coil1'-Coil2' & 5.42 & 1.2 \\
\hline 2 & Coil2-Coil3 & 5.78 & Coil2'-Coil3' & 5.59 & 3.2 \\
\hline 3 & Coil3-Coil4 & 6.04 & Coil3'-Coil4' & 6.22 & 2.8 \\
\hline 4 & Coil4-Coil5 & 3.25 & Coil4'-Coil5' & 6.08 & 46.5 \\
\hline 5 & Coil5-Coil6 & 6.32 & Coil5'-Coil6' & 6.47 & 2.3 \\
\hline 6 & Coil6-Coil7 & 5.88 & Coil6'-Coil7' & 6.25 & 5.9 \\
\hline 7 & Coil7-Coil8 & 7.02 & Coil7'-Coil8' & 7.19 & 2.3 \\
\hline
\end{tabular}




\section{Treatment scheme}

In order to further determine the presence of turn-to-turn short circuit in the rotor, the rotor was returned to the plant for disassembly inspection, and obvious discharge marks were found on the surface of no. 4 coil of the inner ring under the rotor steam side guard ring. The turn-to-turn insulation at the discharge point was carbonized and destroyed, which was located at the straight line at the angle of R, as shown in Figure.2.

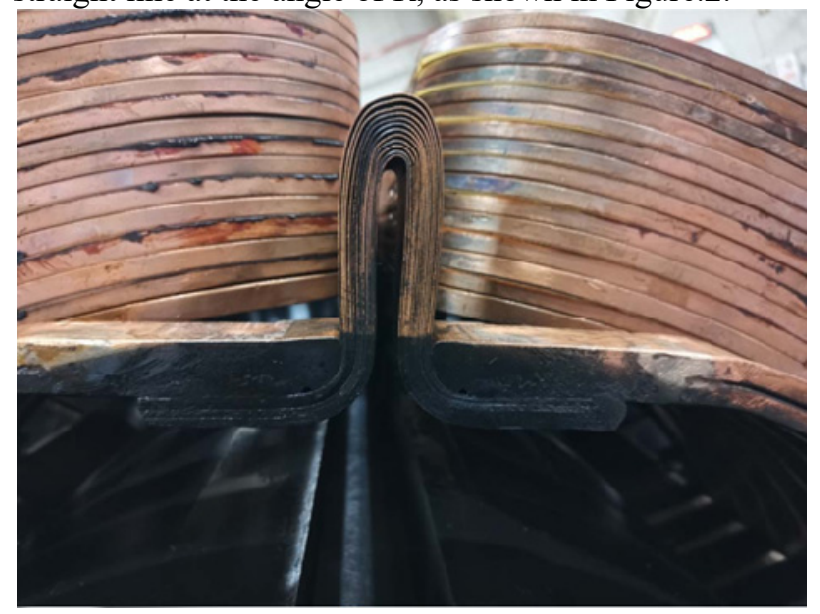

Fig. 2. Position of Turn-to-turn Short

The test waveform of this repetitive surge oscilloscope method is shown in Figure.3. The two returned pulse waveforms are well coincident, and the resultant waveform is $141.403 \mathrm{mV}$ spike pulse at the highest, which indicates that there is no gold or nonmetallic turn-to-turn short circuit fault in the rotor windings.

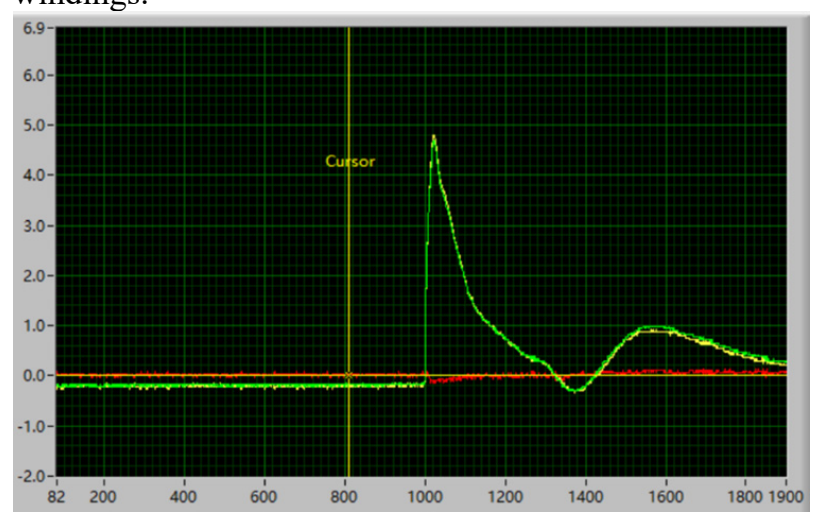

Fig. 3. RSO Test Results

During the overhaul after the rotor is returned to the plant, the plant should make a comprehensive judgment in accordance with the requirements of "Guidelines for The Diagnosis of Turn-to-turn Short-circuit Fault of Hidden Pole Synchronous Generator" (DL/T 1525-2016), combining the static AC impedance and the DC resistance of the rotor windings, and establish a file with the relevant test data to compare and analyze whether there is an deterioration trend of turn-to-turn fault. Measure the insulation qualification of the generator rotor windings before starting each time

Ac impedance and power loss tests at different speeds should be carried out during the unit starting and lifting speed. Before the unit is connected to the grid, the generator zero lift booster test is carried out, and the noload excitation current and excitation voltage values under the generator frontal voltage are recorded for comparison with the ex-factory design values, so as to provide reference criteria for the analysis of the development trend of the generator rotor-turn fault.

In daily operation, should observe the rotor vibration curve and excitation current curve relationship, if I found the rotor vibration value and excitation current value there is an obvious positive correlation, namely the rotor vibration increases with the increasing excitation current increases, reduced with the decrease of the field current, rotor interturn short circuit fault trends should be analyzed whether there is the possibility of degradation. At the same time, observe whether the vibration value of the bearing bush at both ends of the generator increases from the trend, regularly measure the axial voltage, and compare with the historical data to see whether the vibration value increases.

\section{Conclusion}

In this paper, the evidence of turn-to-turn short circuit in a domestic generator is determined by repetitive surge oscilloscope method, and the position of turn-to-turn short circuit is determined by inter-pole voltage method and coil voltage method. With the development of repetitive surge oscilloscope test technology, it has unique advantages in the accuracy and applicability of fault detection and location. Compared with other methods, it is especially suitable for the tracking analysis of generator rotor condition and suitable for popularization. Interelectrode voltage method and coil voltage method are ideal auxiliary tests for repetitive surge oscilloscope test. In the process of diagnosis, if the results of RSO test, interelectrode voltage test and coil voltage test confirm each other that the fault position is consistent, enough attention should be paid to it and further disassembly inspection should be carried out. At the same time, the generator should be combined with the vibration value of bearing bush, axial voltage and other parameters during the daily operation of the generator to establish a data file of the daily operation of the generator, regular observation.

\section{References}

1. Zhikun L, Hongzhong M . Diagnosis for Turn-toturn Short Circuit of Rotor Windingss in Turbo Generator[J]. High Voltage Engineering, 2004.M. Ben Rabha, M.F. Boujmil, M. Saadoun, B. Bessaïs, Eur. Phys. J. Appl. Phys. (to be published)

2. Li, Y., and H. Li . "ON-LINE DIAGNOSIS FOR TURN-TO-TURN SHORT CIRCUIT OF ROTOR WINDINGSS IN TURBO GENERATOR." Automation of Electric Power Systems (2002).F. De Lillo, F. Cecconi, G. Lacorata, A. Vulpiani, EPL, 84 2008. 
3. H. Sun, D. Jiang, J. Ding and J. Yang, "Multifrequency Vibration Suppression of Magnetic Bearing Systems Applied Variable Step-size Automatic Learning Control," 2020 IEEE Energy Conversion Congress and Exposition (ECCE), Detroit, MI, USA, 2020, pp. 3193-3198, doi: 10.1109/ECCE44975.2020.9235914.

4. Yang H, Zhao H . METHOD FOR MEASURING AC IMPEDANCE OF GENERATOR ROTOR AND EFFECTS ON DECISION OF TURN-TOTURN SHORT CIRCUIT FAULT[J]. Automation of Electric Power Systems, 2001.

5. Sivakumar N, Panda S K, Bhangu B, et al. Dynamic model of Brushless Synchronous Generator with turn-to-turn short circuit fault for condition monitoring[C]// Ecce Asia Downunder. IEEE, 2013.

6. Bai, Yinru, Wang, et al. A Novel Concept of Permanent Magnet Synchronous Generators With Automatic Turn-to-Turn Short-Circuit FaultTolerance Capability[J]. IEEE Transactions on Energy Conversion, 2019. 